\title{
Detection of Aquatic Pollution in Meric River by a Measure of Developmental Instability, Fluctuating Asymmetry in the Fish, Common Carp, Cyprinus carpio L., 1758
}

\author{
${ }^{1}$ E.D. Ozsoy, ${ }^{2}$ B. Erkmen, ${ }^{3}$ S.C. Ozeren and ${ }^{1}$ D. Kolankaya \\ ${ }^{1}$ Department of Biology, Faculty of Science, University of Hacettepe, \\ 06800 Beytepe Campus, Ankara, Turkey \\ ${ }^{2}$ Department of Biology, Faculty of Science and Letters, University of Aksaray, Aksaray, Turkey \\ ${ }^{3}$ Department of Biology, Faculty of Science, University of Ankara, 06100 Tandogan, Ankara, Turkey
}

\begin{abstract}
A deviation measure of bilateral symmetry, developmental instability (Fluctuating Asymmetry, FA) was estimated with two different indexes (namely, FAl and FA11) from the samples of common carp, Cyprinus carpio from different collection sites in a highly polluted Meric river system of Turkey. Researchers used three traits of the carp, i.e., head length, eye diameter and barble length to estimate an index of fluctuating asymmetry separately for each trait (FAls) and for the all the three traits combined (FA11s). Only FAl of the eye diameter resulted in significant deviaton from the symmetry when the most polluted site compared to the others. Researchers suggest that developmental instability may be a relevant indicator of pollution as well as the classical markers. We observe as from the study that choice of multiple traits would be helpfull to reveal possible candidates of fluctuating asymmetry for further use in the like model organisms.
\end{abstract}

Key words: Fluctuating asymmetry, Meric river, Cyprinus carpio, pollution, organisms, Turkey

\section{INTRODUCTION}

The developmental stability of an organism is related to its ability to maintain an ideal overall phenotype under a particular set of environments (Zakharov, 1992). When an organism's stability is lowered, it will deviate from this ideal form. In this respect, bilateral structures of bilaterally symmetrical organisms can provide nearly perfect symmetries against which some measure of departure could easily be defined. Fluctuating Asymmetry (FA) is widely used as a measure of developmental stability and defined as a pattern of bilateral variation in a sample of individual organisms. Here, the mean of between-sides (R-L; Right and Left) variation is zero and the distribution is normal and these assumptions are used to describe an ideal FA (Palmer, 1994). Fluctuation Asymmetry (FA) is a population measure of developmental stability and reflects the perturbations of cellular processes that produce trait deviations from developmentally determined bilateral symmetries in the organism (Klingenberg, 2003). FA seems to be almost exclusively environmental in origin and the implication of genetic variance in case-specific FA studies is considered a source of confusion hence, the statistical correction to obtain final FA values (Leung et al., 2003; Palmer and Strobeck, 2003). Overally,
FA might be a good indicator of the effect of environmental history on the developments of a sample of organisms living in a specific environment. For the reasons briefly outlined above, FA is oftenly a reliable measure to determine the extent of antropogenic intrusions into many biological systems (Leung et al., 2003).

In the study researchers tested the extent of aquatic pollution in a river system using FA for multiple marker traits in the fish, common carp, Cyprinus carpio. The river system was Meric of Turkey which is known for its being heavily polluted by various antropogenic sources. The traits were bilaterally structured head length, eye diameter and barble length. Sample (collecting site) FA values are also contrasted to relevant pollution levels obtained from the sampling sites.

\section{MATERIALS AND METHODS}

Sampling and Fluctuating Asymmetry (FA) estimations: locations of sampling sites in the study area is shown in Fig. 1. Five stations were selected for sampling and all samples of common carp (Cyprinus carpio) were collected from May 2002 to August 2003. Ten specimens from each sampling site were collected by

Corresponding Author: B. Erkmen, Department of Biology, Faculty of Science and Letters, University of Aksaray, Aksaray, Turkey 
local fishermen using fishing nets. Concentrations of organochlorine compounds in water, sediments and fish samples are from Erkmen and Kolankaya (2006).

Researchers sampled from the Meric river system, the delta of which is located to where the river pours into the Agean sea (Fig. 1). The delta is in the vicinity of the border between Turkey and Greece and covers a 45,000 ha area which constitutes a huge habitat both for general biological diversity and human agricultural activity. The river has a number of constituent subsystems but the main pollution arises via a branch, Ergene that carries unprocessed wastes from hundreds of industrial activities in Trace. Moreover, domestic wastes and the pollutants from the agricultural areas, especially the rice fields, contribute considerably to the pollution. The sampling stations and their choice criteria are grossly shown in Table 1 .

Common carp, C. carpio samples were collected by local fishermen using fishing nets and traits were measured by a compass on the spot where each collection was performed. The traits were the bilateral head length, eye diameter and barbel length. For fluctuating asymmetry, Palmers FA1 and FA11 (Palmer, 1994) were estimated. FAl is the mean of $|\mathrm{R}-\mathrm{L}|$ (the unsigned

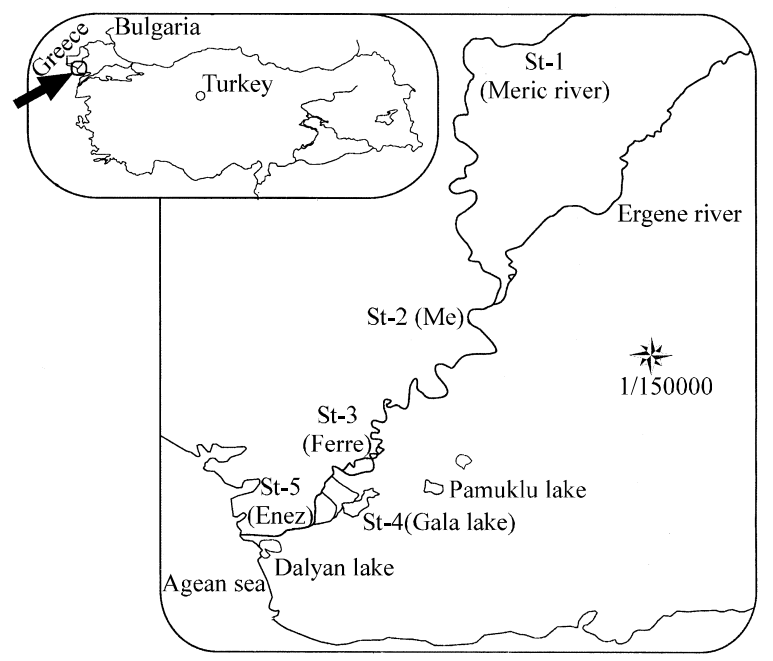

Fig. 1: Study area and sampling sites of Meric delta

Table 1: Collection sites in the study and their choice criteria

\begin{tabular}{ll}
\hline Collection site (station) & Choice criteria \\
\hline Meric river-Kuplu (St-1) & $\begin{array}{l}\text { Site before the main pollution source } \\
\text { Meric-Ergene Junction (St-2) }\end{array}$ \\
$\begin{array}{l}\text { The closest point to the main source } \\
\text { Site of accumulation by coiled water } \\
\text { trajectory }\end{array}$ \\
Enez (St-4) & $\begin{array}{l}\text { The site where the river branching to } \\
\text { the delta does not mix with sea water }\end{array}$ \\
Gala lake (St-5) & $\begin{array}{l}\text { An important reservoir that has } \\
\text { connection to Meric }\end{array}$ \\
\hline
\end{tabular}

difference between right and left sides of a trait) distribution in a sample and the most generally useful index for moderate to large sample sizes. It is easily used in the ANOVA procedure for testing differences among three or more samples (Palmer, 1994). FA11 combines information from multiple traits and may yields an accurate estimate of the overall asymmetry of an individual. It is an estimation that extracts information from all traits into a single index for a sample (Palmer, 1994).

\section{RESULTS AND DISCUSSION}

Environmental contamination of natural waters by pesticide residues is of great concern. The increased use of various types of pesticides particularly organochlorine pesticides has led to concern regarding the potential for contamination of environmental media (i.e., water, sediment and biota) and associated effects on human health and wildlife (Das et al., 2002).

In this study, analyses were carried out on samples from different localities and organisms in Meric delta. Table 2 shows the concentrations of organochlorine pesticide residues in water, sediments and fish samples from study area (Erkmen and Kolankaya, 2006).

Ergene river which is the main tributaries of the Meric river is the main contaminant source in the study area. Because the Meric station takes place before the MericErgene junction with lower contaminant input, it was regarded as a reference region. Other sampling sites in the study area (M-E junction, Ferre, Gala lake and Enez) are subjected to heavy antropogenic pressure (industrial, municipal and agricultural effluents) and they were regarded in the current study as contaminated sites (Erkmen and Kolankaya, 2006). Acording to Erkmen and Kolankaya (2006) organochlorine pesticides and their residues have been widespread through the study area. As shown in Table 2, organochlorine pesticide residues in fish samples were generally higher than residue levels in water and sediment samples. Because of water solubility of the organochlorine compounds, it is expected that any organochlorine pesticides present in the study area will be preferably adsorbed to sediment

Table 2: Total concentrations of organochlorine compounds measured in water, sediments and the fish samples from Meric delta, Turkey (Erkmen and Kolankaya, 2006)

\begin{tabular}{lccc}
\hline & $\begin{array}{c}\text { Water } \\
\text { Sample site }\end{array}$ & $\begin{array}{c}\text { Sediment } \\
\left(\sum \text {-OCPs, ng mL }\right.\end{array}$ & $\begin{array}{c}\text { Fish } \\
\left(\sum \text {-OCPs, ng g }\right.\end{array}$ \\
\hline Meric (St-1) & 1.041 & 3.770 & 1041.22 \\
Meric-Ergene & 2.925 & 11.236 & 1446.26 \\
(St-2) & & & \\
Fere (St-3) & 2.192 & 12.599 & 1798.41 \\
Enez (St-4) & 2.780 & 11.216 & 1758.85 \\
Gala (St-5) & 3.773 & 5.420 & 1034.96 \\
\hline
\end{tabular}


Table 3: Fluctuating asymmetry indexes and their degree of differences among locations. Asymmetries are given for each character (FA1) and for the three traits compiled into a single index (FA11)

\begin{tabular}{lcccc}
\hline Sample location & Traits & No. of individuals & R-L $=$ FA1 (Mean \pm SE) & FA11 (Mean \pm SE) \\
\hline Meric (St-1) & A & 15 & $1.582 \pm 0.491$ & $2.573 \pm 0.279$ \\
& B & 15 & $0.542 \pm 0.116$ & \\
Meric-Ergene (St-2) & C & 15 & $0.667 \pm 0.159$ & $1.193 \pm 0.215$ \\
& A & 27 & $0.429 \pm 0.072^{* * *}$ & $2.787 \pm 0.609$ \\
Ferre (St-3) & B & 27 & $0.950 \pm 0.163$ & \\
& C & 27 & $0.999 \pm 0.163$ & $2.610 \pm 0.340$ \\
Gala (St-4) & A & 33 & $0.497 \pm 0.082^{*}$ & $2.113 \pm 0.290$ \\
& B & 33 & $1.263 \pm 0.182$ & \\
Enez (St-5) & C & 33 & $0.423 \pm 0.069^{* *}$ & \\
& A & 30 & $0.951 \pm 0.144$ & 3.5390 .239 \\
& B & 30 & $1.694 \pm 0.375$ & \\
& C & 30 & $0.898 \pm 0.129^{\mathrm{a}}$ & \\
\end{tabular}

A: Head length, B: Eye diameter; C: Length. SE: Standart Error of the mean. ${ }^{a}$ The trait mean against which all other sample means (for the same trait) were compared; ${ }^{1}$ Measurement in mm, ${ }^{*} \mathrm{p}<0.05 ; * * \mathrm{p}<0.01$

Table 4: Paired t-tests between the mean (in $\mathrm{mm}$ ) of Right (R) and Left $(\mathrm{L})$ sides variation for the eye diameter. This testing allows the detection of Directional Asymmetry (DA) if any

\begin{tabular}{|c|c|c|c|c|c|c|}
\hline \multirow[b]{2}{*}{ Location } & \multirow[b]{2}{*}{ No. of individuals } & \multicolumn{2}{|l|}{ Mean \pm SE } & \multirow[b]{2}{*}{ Mean $|\mathrm{R}-\mathrm{L}|$ difference $\pm \mathrm{SE}$} & \multirow[b]{2}{*}{$\mathrm{t}_{\mathrm{s}}$} & \multirow[b]{2}{*}{$\mathrm{p}$-value } \\
\hline & & $\mathrm{R}$ & $\mathrm{L}$ & & & \\
\hline Meric (St-1) & 15 & $10.331 \pm 0.452$ & $10.236 \pm 0.408$ & $0.095 \pm 0.243$ & 0.391 & 0.699 \\
\hline Meric-Ergene (St-2) & 27 & $9.253 \pm 0.163$ & $9.400 \pm 0.220$ & $0.147 \pm 0.179$ & -0.819 & 0.427 \\
\hline Ferre (St-3) & 33 & $10.915 \pm 0.304$ & $11.118 \pm 0.338$ & $0.203 \pm 0.202$ & -1.010 & 0.322 \\
\hline Gala (St-4) & 30 & $10.443 \pm 0.252$ & $10.490 \pm 0.256$ & $0.050 \pm 0.108$ & -0.432 & 0.669 \\
\hline Enez (St-5) & 24 & $10.304 \pm 0.329$ & $10.225 \pm 0.333$ & $0.079 \pm 0.220$ & 0.360 & 0.722 \\
\hline
\end{tabular}

SE: Standard Error of the mean. ts: Sample t-value. p: Probability that the deviation occurs by chance

or bioaccumulated in fish. Alfa, beta-HCH, p, p'-DDT, p, p'-DDE, Beta-Endosulphan, Heptachlore epoxide and endrine ketone were the most common organochlorine pesticide contaminants in the study area. Samples taken from the reference site were charactarized by the lowest concentrations of the studied contaminants (Erkmen and Kolankaya, 2006).

Table 3 and 4 shows the results of developmental instability. We detected no FAl differences among samples for the individual traits head and barble lengths (coded A and C, respectively Table 3 ). The eye diameter trait (coded $\mathrm{B}$ in the table) however, resulted in significant differences when three samples (Meric-Ergene, Ferre and Gala) were compared to the FAl value of the Enez sample which is the highest among the collection sites (stations) (Table 3). The relatively less polluted site among stations, Meric has no significant value compared to Enez's but this may well be due to smaller sample size in that site (Table 3).

It should be noted all significant differences are exclusively due to the highest FAl value of the Enez sample. As for FA11, the cumulative multitrait index, no differences exist among samples (Table 3). The highest value for this cumulative is of the Enez sampling which clearly arises from the contribution of the eye diameter trait that gives the highest (and significant) individual index (FA1). Because of the conspicuousness of the eye diameter trait, researchers tested the samples for the presence of Directional Asymmetry (DA; one side is considerably larger in this case), one of the important causes that inflate the estimated FAl values in the samples (Palmer, 1994; Palmer and Strobeck, 2003).

The presence of DA is generally considered to indicate the involvement of genetic variance for the asymmetry, blurring the magnitude of environmental effects which are must for an FA based monitoring. Table 4 shows the means for the Right (R) and Left (L) sides variation of eye diameters in the samples. Paired-ttests reveal no significant directed variation in the side lengths for all samples; directional asymmetry is not present in the case of eye diameter trait. Therefore, FAl values on this trait can be considered as reliable estimators of developmental instability in Meric river system in general. The finding of significant asymmetry roughly tracks the pollution profile shown in Table 2 . Moreover, researchers have found a similar rise in activity profile of a mixed function oxidase across the stations (Erkmen and Kolankaya, 2006). Overall, along with the classical markers developmental instability as fluctuating asymmetry seems a relevant indicator of pollution in Meric river system. 


\section{CONCLUSION}

In this study, researchers suggest that use of the deviation from bilateral symmetry (developmental instability; fluctuating asymmetry) could reveal pollution levels as well as the classical markers can do. This may depend on the choice of the marker in a given set of traits of the organism (common carp, Cyprinus carpio) and therefore, multiple trait use would be often better to pick up the good one as in the study.

\section{REFERENCES}

Das, B., Y.S.A. Khan, P. Das and S.M. Shaheen, 2002. Organochlorine residues in catfish, tachysurus thalassinus (ruppel, 1835), from the south patches of the bay of Bengal. Environ. Pollut., 120: 255-259.

Erkmen, B. and D. Kolankaya, 2006. Determination of organochlorine pesticide residues in water, sediment and fish samples from the meric delta, Turkey. Int. J. Environ., 86: 161-169.
Klingenberg, C.P., 2003. A Developmental Perspective on Developmental Instability: Theory, Models and Mechanisms. In: Developmental Instability: Causes and Consequences, Polak, M. (Ed.). Oxford University Press, Oxford, pp: 459-459.

Leung, B., L. Knopper and P. Mineau, 2003. A Critical Assessement of the Utility of Fluctuating Asymmetry as a Biomarker of Anthropogenic Stress. In: Developmental Instability: Causes and Consequences, Polak, M. (Ed.). Oxford University Press, Oxford, pp: 415-426.

Palmer, A.R. and C. Strobeck, 2003. Fluctuating Asymmetry Analysis Revisited. In: Developmental Instability: Causes and Consequences, Polak, M. (Ed.). Oxford University Press, Oxford, pp: 279-319.

Palmer, A.R., 1994. Fluctuating Asymmetry: A Primer. In: Developmental Instability: Its Origins and Evolutionary Implications, Markow, T.A. (Ed.). Kluwer, Dordrecht, Netherlands, pp: 335-364.

Zakharov, V.M., 1992. Population phenogenetics: Analysis of developmental stability in natural populations. Acta. Zool. Fenn., 191: 7-30. 